\title{
Histopathological and ultrastructural studies of synovium in Milwaukee shoulder syndrome-a basic calcium phosphate crystal arthropathy
}

\author{
PAUL B. HALVERSON , ${ }^{1}$ JOHN C. GARANCIS, ${ }^{2}$ AND DANIEL J. MCCARTY \\ From the ${ }^{1}$ Division of Rheumatology, Department of Medicine, and ${ }^{2}$ Department of Pathology, Medical \\ College of Wisconsin, Milwaukee, Wisconsin, USA
}

SUMMARY Light and electron microscopic study of synovial specimens from four patients with the Milwaukee shoulder syndrome disclosed vascular congestion, villous and focal synovial lining cell hyperplasia, occasional giant cells, and fibrin deposition both within and on the surface of the synovium. Although these changes are non-specific, the finding of basic calcium phosphate crystal aggregates in all four cases and the near total absence of an inflammatory reaction are helpful in distinguishing this condition from other types of arthritis. The focal areas of synovial cell hyperplasia may relate to the powerful mitogenic effect of both synthetic and naturally occurring calcium-containing crystals in concentrations found in the synovial fluid of these patients.

Key-words: hydroxyapatite, endocytosis, synovial hyperplasia.

We have recently described 15 patients with a peculiar large joint arthropathy involving the shoulder and to a lesser extent the knee which we called the Milwaukee shoulder syndrome (MSS). ${ }^{1-3}$ Features included female predominance, more severe involvement on the dominant side, glenohumeral joint osteoarthritis, rotator cuff defects, and nearly acellular synovial fluids containing basic calcium phosphate crystals (BCP), ${ }^{4}$ particulate collagen types I, II, and III, and elevated collagenase and non-specific neutral protease activities.

Pathological description was presented on one patient (A) who underwent shoulder synovectomy. ${ }^{5}$ Gross examination and microscopic analysis showed extensive osteochondromatosis. Electron microscopy showed calcific deposits in synovial microvilli which appeared to have access to the joint space through areas denuded of synovial cells. Three more patients with MSS have since had shoulder surgery performed. After study of these additional synovial

Accepted for publication 22 March 1984.

Correspondence to Professor D. J. McCarty, Department of Medicine, Medical College of Wisconsin, Milwaukee County Medical Complex, 8700 West Wisconsin Avenue, Milwaukee, Wisconsin 53226, USA. specimens the pathological findings in patient $\mathrm{A}$ were reviewed and the additional findings uncovered are also presented here.

\section{Case reports}

$\mathrm{B}$ is a 60 -year-old woman who had a one year history of right shoulder pain following a fall on the outstretched right hand. Fourteen years earlier she had had bilateral calcific tendonitis treated by $x$-irradiation. She underwent implantation of a subacromial spacer on 9 July 1981 . When the joint capsule of the right shoulder was entered, a large volume of synovial fluid was encountered. The synovium was boggy and hyperplastic. Synovial biopsies were obtained. Destructive changes included complete absence of the rotator cuff, absence of the long head of the biceps tendon, and degenerative changes in the greater tuberosity of the humerus. There was subluxation of the humeral head cephalad to a position adjacent to the inferior aspect of the acromion.

The articular cartilage on the humeral head was smooth, as was most of the cartilage of the glenoid fossa except for some irregularity noted on the superior aspect of the glenoid. This area did not 
Histopathological and ultrastructural studies of synovium in Milwaukee shoulder syndrome

Table 1 Synovial histological findings in four patients with Milwaukee shoulder syndrome

\begin{tabular}{|c|c|c|c|c|c|c|c|c|}
\hline Patient & $V H$ & $H S C$ & $F i b$ & Calc & $G C^{\circ}$ & $V C$ & $I n f l$ & Fibr \\
\hline A & ++++ & ++++ & ++++ & +++ & $+t$ & $+++t$ & - & ++ \\
\hline B & +++ & $++t$ & ++++ & +++ & ++ & +++ & - & + \\
\hline $\mathrm{C}$ & +++ & +++ & ++- & ++ & ++ & +++ & - & + \\
\hline D & + & ++ & + & $+++t$ & + & + & - & ++++ \\
\hline
\end{tabular}

$\mathrm{VH}=$ villous hyperplasia. $\mathrm{HSC}=$ hyperplasia of synovial cells. Fib=fibrin. GC=giant cells. $\mathrm{VC}=$ vascular congestion. Infl=inflammation. $\mathrm{Fibr}=$ fibrosis. Calc $=\mathrm{BCP}$ crystal aggregates .

articulate with the humerus in the anatomic position.

C, a 72-year-old woman, underwent surgery on the right shoulder 11 November 1982 following severe pain for the preceding 18 months. When her shoulder joint capsule was entered, a large amount of cloudy yellow fluid was encountered. The capsule was patulous and the rotator cuff was completely absent. Synovial thickening and increased villous formation were noted. Biopsies were taken. Marked articular cartilage degeneration was apparent, with eburnation of the glenohumeral surfaces. The superior aspect of the humeral head beneath the acromion showed pitting. Because of the articular cartilage damage, the humeral head was amputated at the anatomical neck, and a large Neer humeral prosthesis was fixed in its place. A polyethylene subacromial spacer was fixed beneath the acromion to depress the prosthesis into the glenoid fossa.

D, a 61-year-old man, had recurrent right shoulder dislocations for about six years. In 1979 a Michael Reese total shoulder joint prosthesis was surgically implanted. In 1980 the patient was operated on for removal of the prosthesis because of loosening of the glenoid component. When the joint capsule of the right shoulder was incised, a large amount of synovial fluid was released. Rice bodies were observed in the fluid and covering the synovium. A partial synovectomy was performed, and the tissue was noted to contain calcific material on gross examination.

\section{Methods}

All specimens for light microscopy were fixed in neutral $10 \%$ formalin and stained with haematoxylin and eosin ( $\mathrm{H}$ and $\mathrm{E})$. Movat's stain was used to study fibrin deposits and calcium deposits were demonstrated by Van Kossa stain. ${ }^{6}$ A slice of tissue was taken from the biopsy specimen and cut into five or six blocks, each approximately $2 \mathrm{~cm}$, and processed for electron microscopy. The blocks were fixed in Karnovsky's solution, postfixed in $1 \%$ osmium tetroxide, and embedded in Spurr's lowviscosity epoxy resin. Sections were stained with lead citrate and uranyl acetate and examined with an RCA EMU-4B electron microscope at 50KV. Unstained sections were examined by STEM electron microscopy (Phillips model 400T) and subjected to study by $x$-ray energy dispersive analysis.

\section{Results}

L.IGHT MICROSCOPY

Light microscopy findings are summarised in Table 1. The synovial membrane showed focal villous hyperplasia. Some villi formed multiple peripheral branches resulting in a papillary structure (Fig. 1).

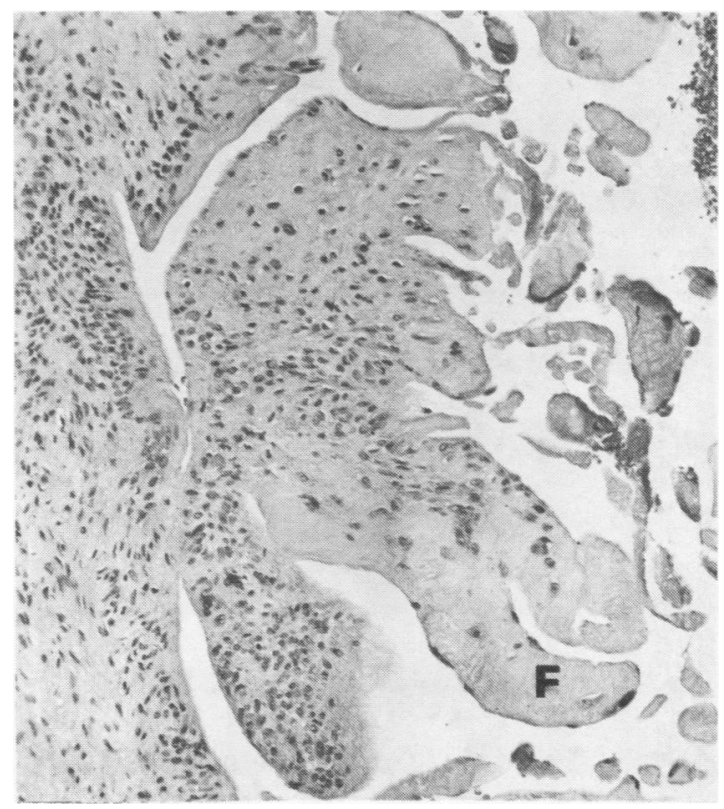

Fig. 1 (Patient A) Villous hyperplasia. Many villi were partly covered with fibrin deposits (F). Synovial stroma is hypercellular. $(\times 100, H$ and $E)$. 
In cross-sections they appeared as free floating bodies. The fibrous tissue core of villi contained proliferating arterioles and venules. Vascularity was minimal in the peripheral branches of villi. The synovial membrane had a continuous surface lining of round or slightly elongated cells, generally not exceeding more than three layers. However, in many areas there was marked focal hyperplasia of the synovial lining cells. They formed several layers as many as 10 cells deep (Fig. 2). Although the cellular hyperplasia was seen randomly, it occurred more often on the synovial villi and at the base of the surface invaginations. Formation of isolated multinucleated giant cells was observed in hyperplastic areas of the synovial lining frequently located adjacent to crystal deposits (Fig. 2).

The most common site of crystal deposition was in the synovial stroma, which in many areas showed marked hypercellularity and formation of few giant cells (Fig. 3). In some areas crystal deposits were associated with extensive stromal scarring (Fig. 4).

Movat's stain confirmed the fibrin nature of the deposits on the synovial surface. Apparently the fibrin was deposited at different times. Some deposits were recent, but others showed various stages of organisation. There was infiltration by the stromal cells at the base of fibrin deposits and continuous

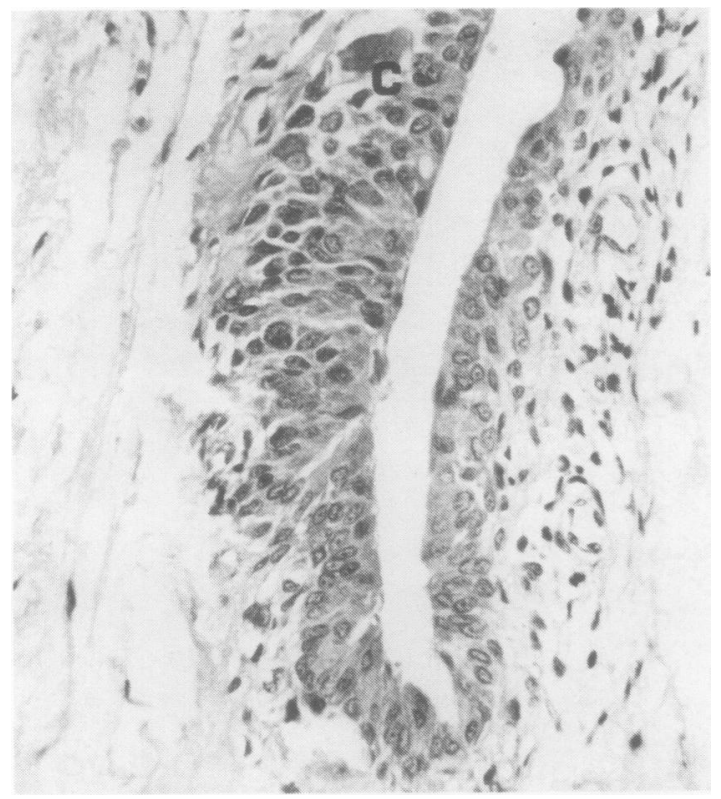

Fig. 2 (Patient A) Synovial surface invagination with hyperplasia of the synovial lining cells. Multinucleated giant cell $(\mathrm{C}) .(\times 176, H$ and $E$ stain $)$.

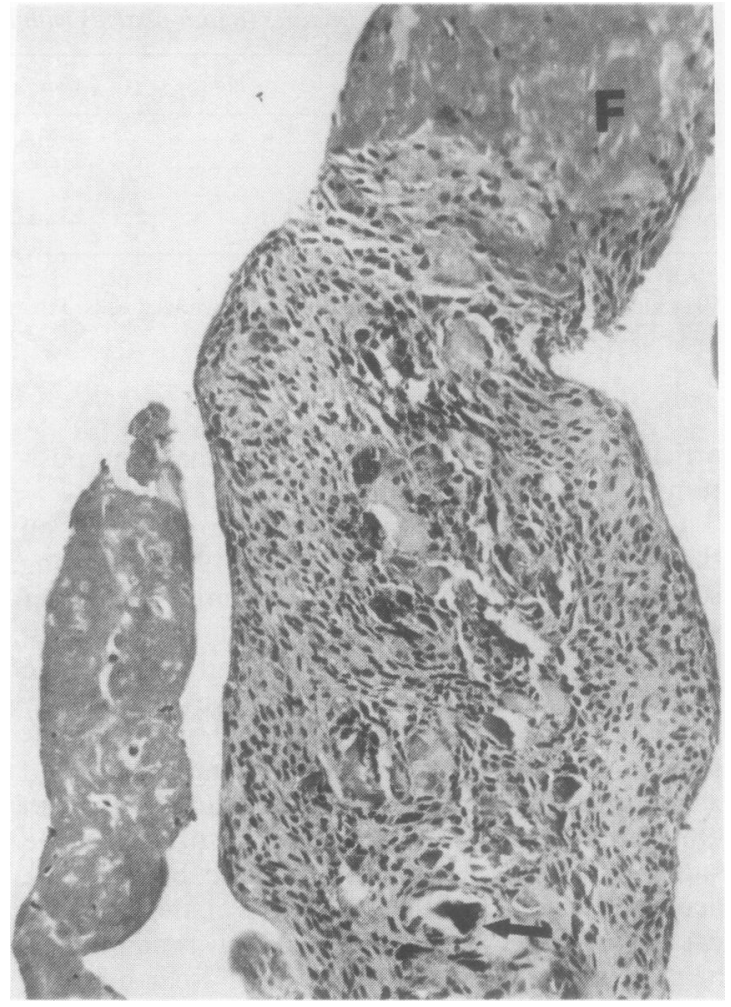

Fig. 3 (Patient B) Crystal deposits (arrow) appear in hypercellular stroma. Few giant cells are present. Fibrin deposits $(\mathrm{F}) .(\times 110$, Movat's stain $)$.

growth of the surface lining cells on the free surface of deposits. Of interest is that the synovial tissues of all four cases showed no inflammatory reaction, acute or chronic.

\section{ELECTRON MICROS COPY}

There were several layers of surface lining cells, not more than three cells thick (Fig. 5). The cells were separated by wide intercellular spaces containing a mixture of fibrin, crystals, and amorphous material. The majority of cells had attenuated smooth cytoplasm. Some cells had formed short cytoplasmic projections which partially or completely surrounded the intercellular material, suggestive of a phagocytic process. Many pinocytotic vesicles were present at the luminal and basal surfaces of the synovial lining cells. Other cytoplasmic organelles such as mitochondria, granular endoplasmic, reticulum, and RNA particles were sparse.

Hyperplastic synovial lining consisted of large irregular cells separated from each other by ex- 


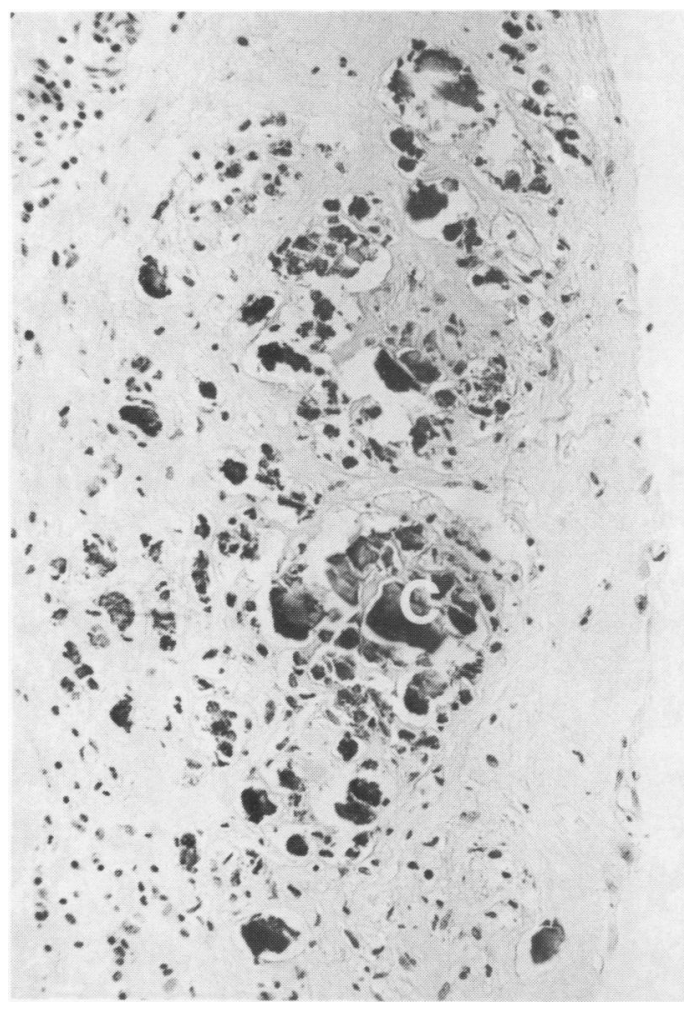

Fig. 4 (Patient D) Marked synovial scarring due to crystal deposits $(\mathrm{C}) .(\times 110$, H and E stain $)$.

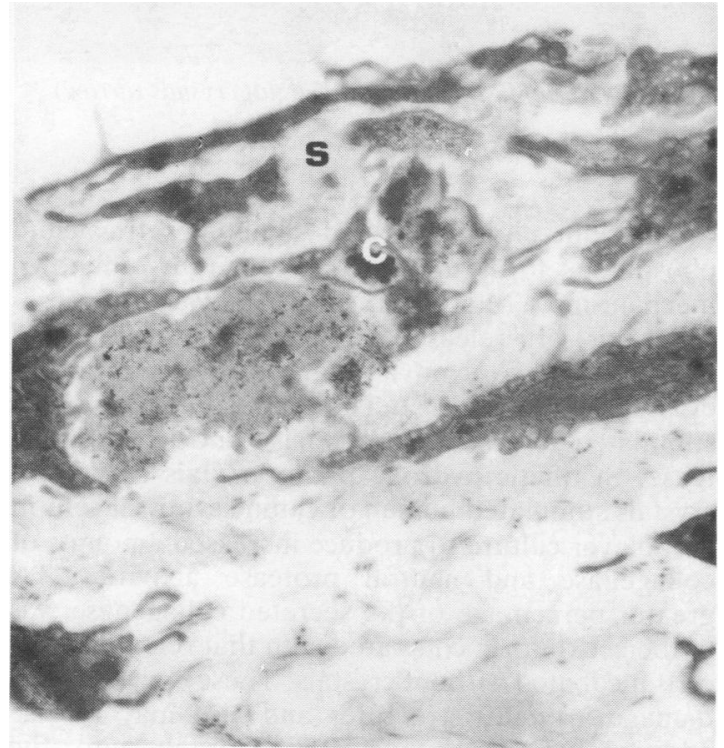

Fig. 5 (Fatient A) Electon micrograph of synovial surface lining cells separated by wide intercellular space (S). Crystal deposits $(\mathrm{C}) .(\times 10200)$. tremely wide intercellular spaces (Fig. 6). Each cell produced extensive cytoplasmic processes forming complex interdigitations with the adjacent cells. The intercellular material, fibrin and crystals, were actively phagocytosed by the surface lining cells (Fig. 7). Occasionally small secondary lysosomes containing crystals were observed. These had a distinct continuous limiting membrane (Fig. 8). Other larger crystal aggregates were also observed within the cytoplasm that were not surrounded by a limiting membrane. In addition the cytoplasm contained well developed granular endoplasmic reticulum, many mitochondria, and numerous pinocytotic vesicles (Fig. 6).

In some areas the surface lining cells were missing, and the denuded synovial membrane was covered by masses of fibrin in which variably sized crystal aggregates were embedded (Fig. 9). Fibrin was recognised by the presence of characteristic cross-striated fibres. The synovial membrane consisted of interrupted layers of synovial cells (fibrocytes) and collagen fibres embedded in connective tissue matrix. The synovial cells had abundant cytoplasm with well developed granular endoplas-

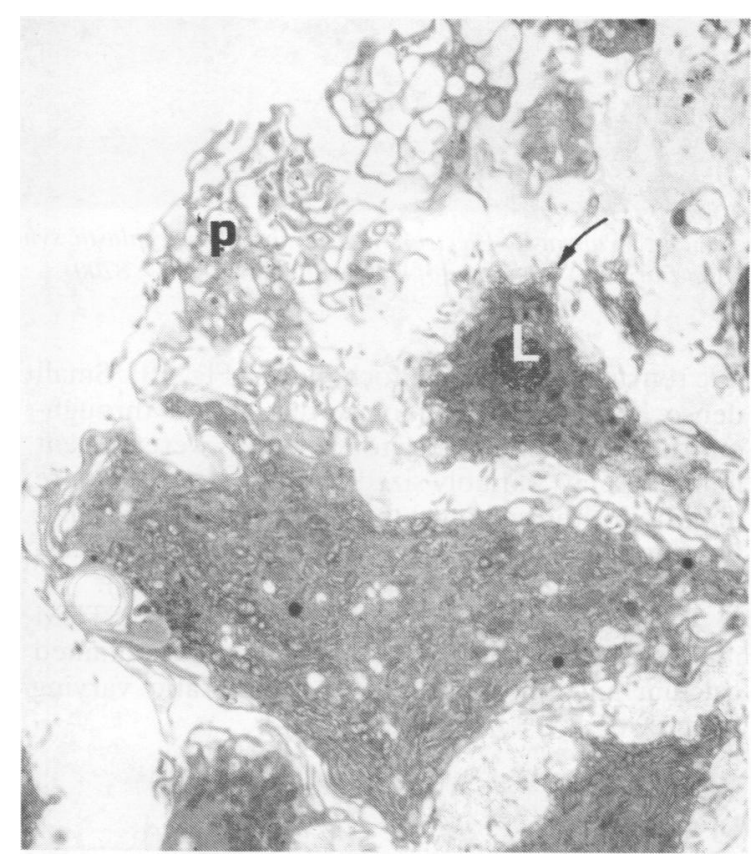

Fig. 6 (Patient B) Electron micrograph of hyperplastic synovial lining cells forming extensive cytoplasmic processes (P); secondary lysosomes $(\mathrm{L})$; pinocytotic vesicles (arrow) $(\times 4930)$. 


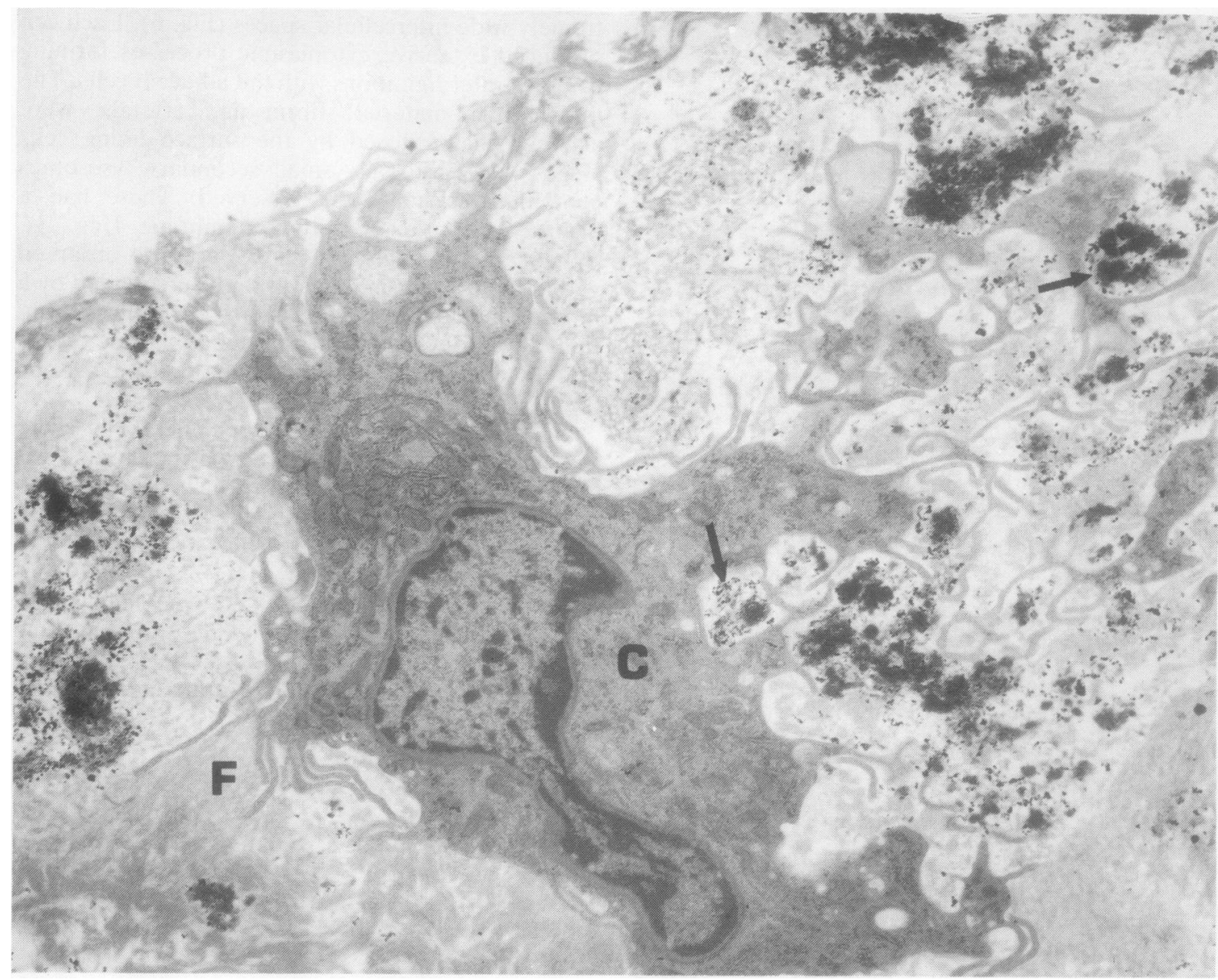

Fig. 7 (Patient () Electron micrograph of hyperplastic synovial cell (C). (ytoplasmic processes c'ngulf crastals (arrow) and fibrin $(\mathrm{F})$ indicative of active phagocytosis $(\times 8700)$.

mic reticulum and few mitochondria (Fig. 10). Small dense bodies were randomly distributed throughout the cytoplasm. Pinocytotic vesicles were present in many cells. Variably sized crystal aggregates were deposited throughout the synovial membrane. Occasionally crystals were surrounded by cytoplasmic processes of the synovial cells (Fig. 11).

$X$-ray energy dispersive analysis under STEM microscopy showed that the crystals contained calcium and phosphorus in a molar ratio varying from 1.4 to 1.7 .

\section{Discussion}

We have formulated a tentative hypothesis regarding the pathogenesis of MSS. ${ }^{1}$ BCP crystals, consisting of partly carbonate-substituted hydroxyapatite, octacalcium phosphate, and sometimes tricalcium phosphate, form in synovial tissue by unknown mechanisms. ${ }^{4}$ Microaggregates of crystals (microspheroids) are released into the synovial fluid and phagocytosed by synovial lining cells or are phagocytosed in situ (Fig. 8). The synovial cell is in turn stimulated to secrete collagenase and neutral protease. Synthetic hydroxyapatite crystals or natural crystals stimulated human or canine synovial cells in monolayer culture to produce increased amounts of collagenase and neutral protease activities. ${ }^{7} \mathrm{~A}$ greater percentage of the secreted collagenase was in the active form compared with that released from cells incubated without crystals. These enzymes may damage articular structures and also may release additional tissue bound BCP crystals into the synovial fluid to continue the cycle. ${ }^{8}$ This mechanism, which we have called 'enzymatic strip-mining', 
could also account for the particulate collagens uniformly found in these patients' joint fluids. ${ }^{24}$ Incubation of partially purified mammalian collagenase with minced synovium containing crystal aggregates released these from the tissue. ${ }^{8}$ Moreover, the mean diameter and size range of the crystal aggregates released as measured by scanning electron microscopy was identical to that found in the synovial fluids obtained from the same patient.

The frequent observation of pinocytotic vesicles in the synovial cells (Figs. 6 and 11) suggests that these cells may release enzymes by exocytosis. Synovial cells have been reported to release enzymes by this mechanism when stimulated by ingested particles or soluble products of activated lymphocytes. ${ }^{9} 10$

The synovial changes observed in MSS consisted of villous and synovial lining cell hyperplasia, giant cell formation, fibrin, and BCP crystal deposition (Figs. 1-3). The previous report describing tissue obtained from $\mathrm{KH}$ emphasised only the findings of crystals in the subsynovium and chondromatosis. ${ }^{5}$ Many of these histological features are not specific and have been observed in osteoarthritis, rheumatoid arthritis, and systemic lupus erythematosus. ${ }^{11}$ The concomitant finding of aggregates of $\mathrm{BCP}$ crystals and the near total absence of an inflammatory reaction are helpful in distinguishing MSS from other common rheumatic diseases. In the other crystal deposition arthropathies, gout and pseudogout, characterised respectively by the presence of monosodium urate monohydrate and calcium pyrophosphate dihydrate crystals, there is an infiltration of polymorphonuclear leucocytes and lymphocytes into the synovium. But in MSS crystal deposits in the synovial membrane elicited only interstitial cell hyperplasia and focal giant cell formation. At most only a few lymphocytes were observed.

The focal areas of synovial cell hyperplasia found here may relate to our recent finding that $\mathrm{BCP}$ crystals, both synthetic and naturally occurring, are powerful mitogens when added to cultured synovial cells or skin fibroblasts. ${ }^{12}$ And they were mitogenic in concentrations of $5-50 \mu \mathrm{g} / \mathrm{ml}(\mathrm{mg} / \mathrm{l})$, precisely the levels found in synovial fluid. ${ }^{2}$ Such crystals failed to stimulate non-phagocytic cells such as lymphocytes, Mitogenesis was invariably accompanied by crystal phagocytosis. All calcium-containing crystals tested showed mitogenic activity (for example, calcium urate, calcium pyrophosphate dihydrate, calcium diphosphonate) whereas non-calcium containing crystals or inert particles such as latex beads did not. Calcium-45 labelled crystals were solubilised by phagocytic cells, and solubilisation could be inhibited by weak bases such as chloroquine or ammo-

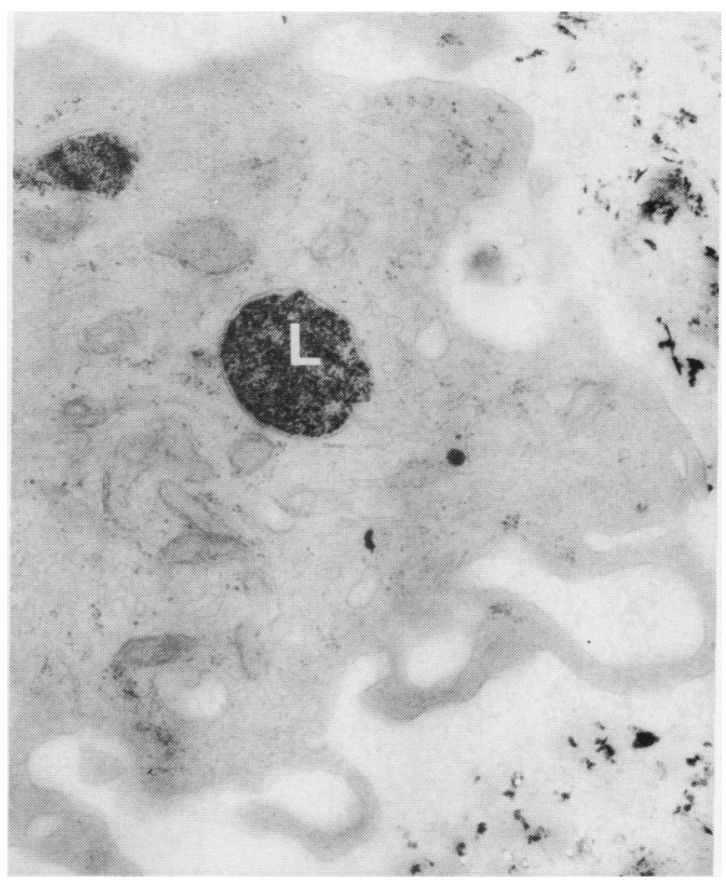

Fig. 8 (Patient C) Electron micrograph of hyperplastic synovial cells with secondary lysosomes $(\mathrm{L})$ containing crystals. Lysosomes have distinct limiting membranes $(\times 22600)$.

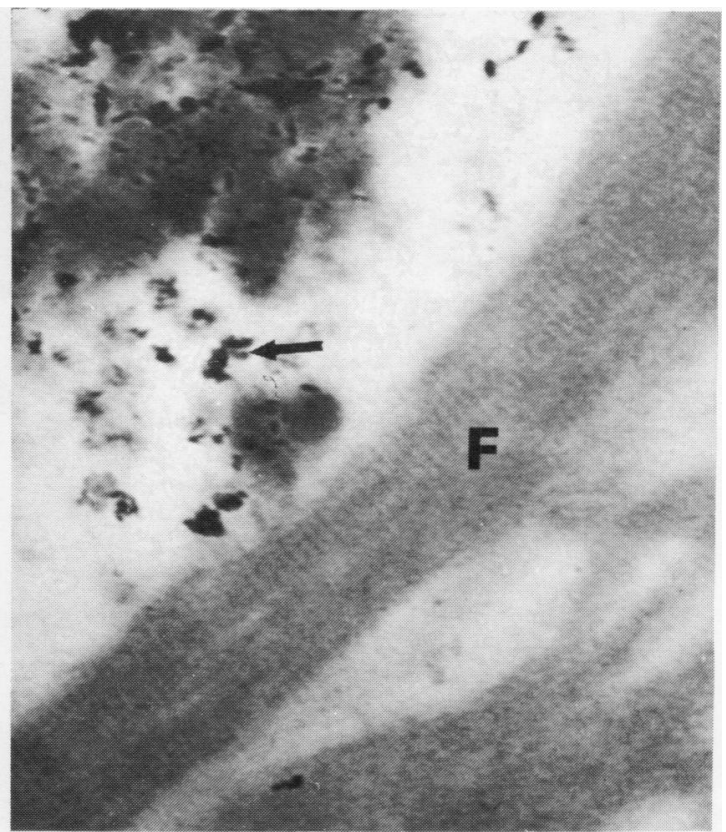

Fig. 9 (Patient C) Electron micrograph of fibrin deposits (F) consisting of cross-striated fibres. Crystals (arrow). ( $\times 58600)$. 


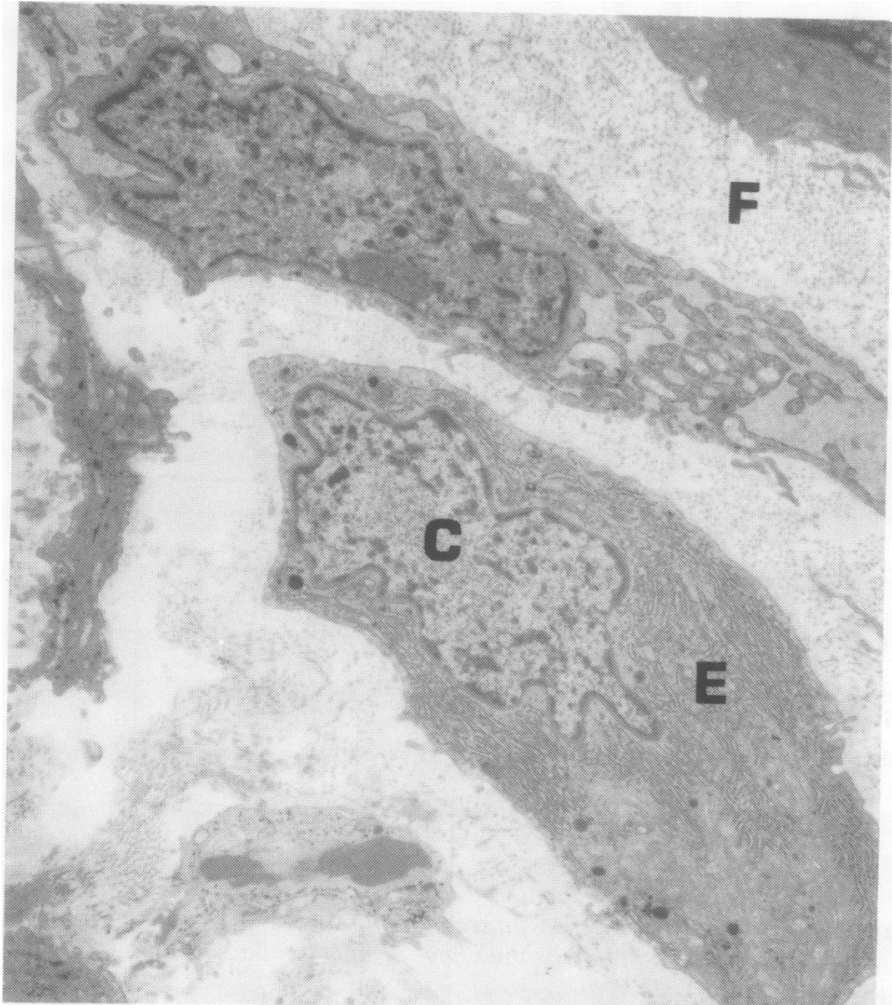

Fig. 10 (Patient C) Electron micrograph of synovial membrane. Synovial cells resemble fibrocytes (C). Endoplasmic reticulum (E) Collagen Fibres (F). $(\times 5800)$

Fig. 11 (Patient B) Electron micrograph of synovial membrane. Crystals (C) surrounded by cytoplasmic processes of synovial cells. Pinocytotic vesicles (arrow). $(\times 12600)$.

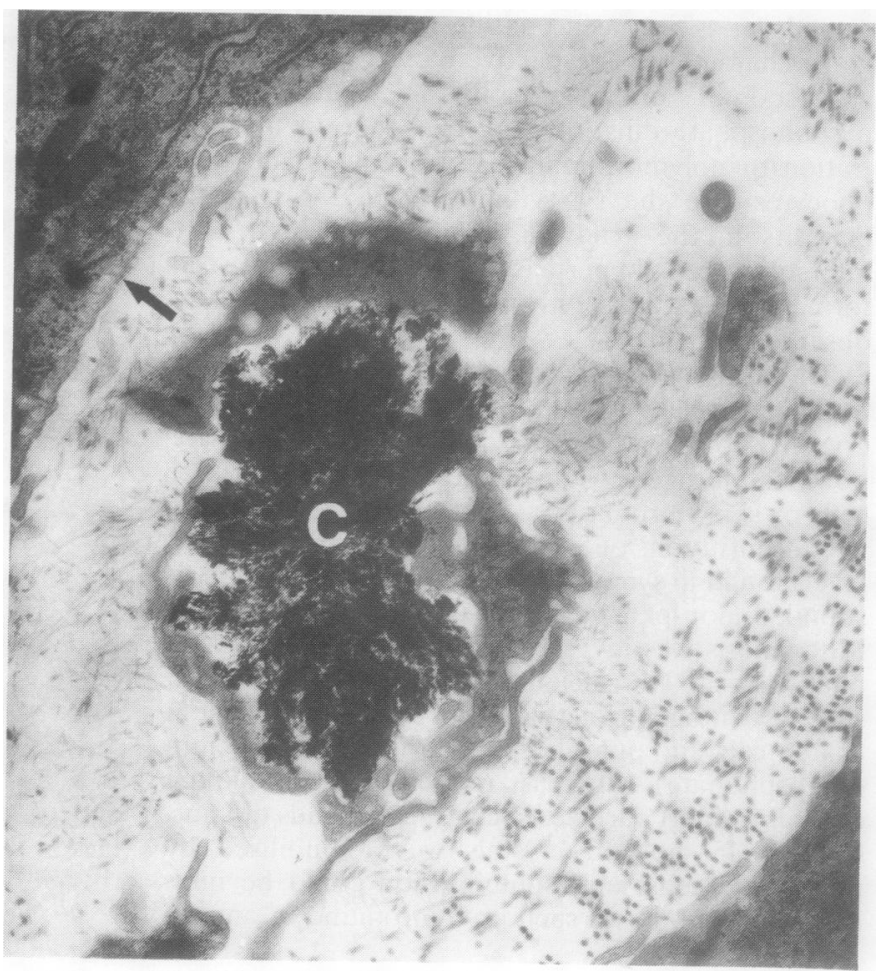


nium, which are known to raise the $\mathrm{pH}$ in secondary lysosomes. ${ }^{13}{ }^{14}$ Mitogenesis induced by calcium crystals was inhibited to a much greater extent than that induced by serum by similar concentrations of weak base. ${ }^{1+}$ Taken together these data suggest that crystal solubilisation may raise the intracellular calcium level, a known mitogenic stimulus.

In some areas extensive synovial fibrosis and hyalinisation accompanied crystal deposition. Vascular congestion and synovial cell proliferation were seen as in some other arthropathies, such as rheumatoid arthritis, but a perivascular inflammatory cell infiltration was absent.

Extensive deposits of fibrin were associated with severe vascular congestion and loss of the synovial surface lining. Electron microscopy demonstrated that the fibrin deposits characteristically contained BCP crystal aggregates which may have been picked up from the synovial fluid. The significance of the fibrin accumulation is not known. Some but not all of these affected shoulder joints were unstable, ${ }^{1}$ and few or many erythrocytes were commonly noted in fluids obtained from them. ${ }^{2}$

Physiological measurements of the passage of protein molecules from plasma to synovial fluid have demonstrated a close correlation with the severity of inflammation. ${ }^{15} 16$ Protein molecules appeared in joint fluid in proportion to their Stokes radius. The low fibrinogen (MW 340000 ) levels in all but the most severely inflamed joints ${ }^{16}$ have been attributed to the very large Stokes radius of this non-globular, elongated molecule. ${ }^{17}$

\section{References}

1 MeCarty D J. Halverson P B. Carrera G F. Brewer B J. Kozin F K. Milwaukee shoulder: association of microspheroids containing hydroxyapatite crystals, active collagenase and neutral protease with rotator cuff defects. I. Clinical aspects. Arthritis Rheum 1981; 24: 464-73.

2 Halverson P B. Cheung H S, McCarty D J. Garancis J C. Mandel N. Milwaukee shoulder: association of microspheroids containing hydroxyapatite crystals, active collagenase and neutral protease with rotator cuff defects. II. Synovial fluid studies. Arthritis Rheum 1981: 24: 474-83.
3 Halverson P B. McCarty D J, Cheung H S, Ryan L R. The Milwaukee shoulder syndrome: report of 11 additional cases with involvement of the knee in seven. Semin Arthritis Rheum in press.

4 McCarty D J. Lehr J R. Halverson P B. Crystal populations in human synovial fluid. Identification of apatite, octacalcium phosphate and tricalcium phosphate. Arthritis Rheum 1983; 26: $1220-4$.

5 Garancis J C. Cheung H S. Halverson P B. McCarty D J. Milwaukee shoulder: association of microspheroids containing hydroxyapatite crystals, active collagenase and neutral protease with rotator cuff defects. III. Morphologic and biochemical studies of an excised synovium showing chondromatosis. Arthritis Rheum 1981: 24: 484-91.

6 Sheenan D C. Hrapchak B B. Theory and practice of histotechnology. St Louis, New York, London: Mosby, 1980: 198.

7 Cheung H S, Halverson P B, McCarty D J, Garancis J C. Release of collagenase, neutral protease and prostaglandins from cultured synovial cells by hydroxyapatite and calcium pyrophosphate dihydrate. Arthritis Rheum 1981; 24: 1338-44.

8 Halverson P B. Cheung H S. McCarty D J. Enzymatic release of microspheroids containing hydroxyapatite crystals from synovium and of calcium pyrophosphate dihydrate crystals from cartilage. Ann Rheum Dis 1982; 41: 527-31.

9 Dayer J M. Russell R G G. Krane S M. Collagenase production by rheumatoid synovial cells: stimulation by a human lymphocyte factor. Science 1977; 195: 181-3.

10 Werb Z. Reynolds J J. Stimulation by endocytosis of the secretion of collagenase and neutral protease from rabbit synovial fibroblasts. J Exp Med 1974: 140: 1482-97.

11 Goldenberg D L. Cohen A S. Synovial membrane histopathology in the differential diagnosis of rheumatoid arthritis, gout, pseudogout, systemic lupus erythematosus, infectious arthritis and degenerative joint disease. Medicine (Baltimore) 1978; 57: 239-52.

12 Cheung H S. Story M T. McCarty D J. Mitogenic effects of hydroxyapatite and calcium pyrophosphate on cultured mammalian cells. Arthritis Rheum 1984; 27: 668-74.

13 Evans R W, Cheung H S, McCarty D J. Cultured canine synovial cells solubilise ${ }^{45} \mathrm{Ca}$ labelled hydroxyapatite crystals. Arthritis Rheum 1984: 27: 829-32.

14 Cheung H S, McCarty D J. Intracellular dissolution is essential for mitogenesis induced by crystals containing calcium (abstr). Arthritis Rheum 1984; 27: 549.

15 Kushner I, Somerville J A. Permeability of human synovial membranes to plasma proteins. Arthritis Rheum 1971; 14: 560-70.

16 Gardner D L. The pathology of rheumatoid arthritis. Baltimore: Williams and Wilkins, 1972; page 20.

17 Simkin P A. Synovial membrane physiology. In: McCarty D J, ed. Arthritis and allied conditions. 10th ed. Philadelphia: Lea and Febiger, 1984: 196-209. 